\title{
BMJ Open Implementation and initial analysis of Cardiff Model data collection procedures in a level I trauma adult emergency department
}

\author{
Peter Nguyen (D) , ${ }^{1}$ Sara A Kohlbeck (D) , ${ }^{2}$ Michael Levas, ${ }^{2}$ \\ Jennifer Hernandez-Meier (1D) 2,3
}

To cite: Nguyen $P$,

Kohlbeck SA, Levas M, et al. Implementation and initial analysis of Cardiff Model data collection procedures in a level I trauma adult emergency department. BMJ Open 2022;12:e052344. doi:10.1136/ bmjopen-2021-052344

- Prepublication history for this paper is available online. To view these files, please visit the journal online (http://dx.doi. org/10.1136/bmjopen-2021052344).

Received 26 April 2021 Accepted 01 November 2021

Check for updates

(c) Author(s) (or their employer(s)) 2022. Re-use permitted under CC BY-NC. No commercial re-use. See rights and permissions. Published by BMJ.

${ }^{1}$ School of Medicine, Medical College of Wisconsin,

Milwaukee, Wisconsin, USA

${ }^{2}$ Comprehensive Injury Center, Medical College of Wisconsin, Milwaukee, Wisconsin, USA

${ }^{3}$ Emergency Medicine,

Medical College of Wisconsin, Milwaukee, Wisconsin, USA

Correspondence to

Dr Jennifer Hernandez-Meier; jhernandez@mcw.edu

\section{ABSTRACT}

Objectives Our understanding of community violence is limited by incomplete information, which can potentially be resolved by collecting violence-related injury information through healthcare systems in tandem with prior data streams. This study assessed the feasibility of implementing Cardiff Model data collection procedures in the emergency department (ED) setting to improve multisystem data sharing capabilities and create more representative datasets.

Design Information collection fields were incorporated into the ED electronic health record (EHR), which gathered additional information from patients reporting assaultive injuries. ED nurses were surveyed to evaluate implementation and feasibility of information collection. Logistic regression was performed to determine associations between missing location information and patient demographic data.

Setting 60-bed academic level I trauma adult ED in a large Midwestern city.

Participants 2648 patients screened positive for assault injuries between 2017 and 2020. 198 patients were omitted due to age outside the range served by this ED. Unselected inclusion of 150 ED nurses was surveyed.

Main outcome measures Main outcomes include nursing staff survey responses and ORs for providing complete injury information across various patient demographics. Results Most ED nurses believed that information collection aligned with the hospital's mission (92\%), wanted information collection to continue (88\%), did not believe that information collection impacted their workflow (88\%), and reported taking under $1 \mathrm{~min}$ to screen and document violence information (77\%). 825 patients (31.2\%) provided sufficient information for geospatial mapping. Likelihood of providing complete location information was significantly associated with patient gender, race, arrival means, accompaniment, trauma type and year.

Conclusions It is feasible to implement information collection procedures about location-based, assaultrelated injuries through the EHR in the adult ED setting. Nurses reported being receptive to collecting information. Analyses suggest patient-level and time variables impact information collection completeness. The geospatial information collected can greatly improve preexisting law enforcement and emergency medical systems datasets.
Strengths and limitations of this study

- The duration of this study spanned over 3 years, which is currently the longest published investigation of this additional emergency department information collection in the USA.

- We include multiple modalities of information to assess overall feasibility of the information collection, including data abstraction from electronic health records and self-report surveys with nurses.

- We were able to incorporate several variables that may impact information completeness, including demographics (gender, race, age, insurance payer status), incident-level variables (means of arrival, accompaniment, trauma type) and time-varying variables (season, time of day, year).

- Our low nurse survey response rate may not provide an accurate representation of the whole nursing staff.

- Finally, the study is conducted at one medical centre and may not be generalisable to other hospitals or healthcare systems in the USA.

\section{BACKGROUND AND SIGNIFICANCE}

Current model policing: incomplete data to guide violence-related decisions

Community violence is a significant public health issue in the USA. An estimated 5 million assault-related injuries occurred in 2018. ${ }^{1}$ Current law enforcement decision-making and resource allocation use predictive geographical models created exclusively from law enforcement data. ${ }^{2}$ Advancements in model predictive accuracy have enabled more robust discussions around community violence than were possible with hotspot mapping alone. However, significant limitations of solely relying on law enforcement data remain since datasets are incomplete and do not accurately represent community violence due to underreporting of violent crimes. Studies show that $43 \%$ of violent crimes are 
reported to law enforcement ${ }^{1}$ and between $52.9 \%$ and $59 \%$ of assault incidents are not reported to police. ${ }^{34}$ This limitation is shown again with an $11 \%$ overlap between law enforcement and hospital-based information on assault victims. ${ }^{5}$ Supplementation of current law enforcement data with electronic health record (EHR) information from hospitals may provide a more comprehensive model for understanding, mitigating and preventing community violence.

\section{Current approaches for violence prevention}

Numerous governmental, public health and community-based efforts have addressed community violence. Examples include public awareness campaigns, violence prevention and intervention strategies integrated into school curriculum, environmental modifications, improvements in comprehensive public health strategies and policy changes. ${ }^{67}$ Coalition stakeholders typically represent schools, universities, state agencies, community-based organisations and law enforcement. Hospital institutions historically have not been included within these multidisciplinary groups even though healthcare services ubiquitously serve victims of violence. In response, increasing numbers of healthcare systems in the USA have developed their own violence prevention strategies, collectively termed hospital-based violence intervention programmes, which aim to interrupt costly cycles of retaliation seen in survivors of violent injuries. ${ }^{89}$ Community-based, law enforcement-based and hospital-based methods incrementally decrease community violence. However, lack of open collaboration and information sharing between government agencies, community coalitions and hospitals poses significant limitations on innovation, application of novel approaches and efficient use of resources.

\section{The Cardiff Model: an integrated approach}

Around 1.5 million assaultive injuries are treated in US emergency departments (EDs) each year. ${ }^{10}$ Hospitals have substantial potential to gather information to inform current violence prevention efforts. The Cardiff Model accomplishes this by leveraging deidentified assault-related injury information collected in EDs to enhance the overall understanding of community violence. Prior pilot studies from around the globe demonstrated Cardiff Model feasibility and adequate patient information collection about assaultive injuries in the healthcare setting. ${ }^{11-14}$ Information collected includes time and location of the assault, and weapon(s) used. This information is then deidentified, aggregated and analysed in tandem with law enforcement data. Summary reports are generated and shared with community stakeholders, law enforcement partners and community violence intervention programmes at regular meetings to foster discussion and solutions. The Cardiff Model groundwork involves information sharing and continued collaboration between stakeholders to develop and enhance comprehensive violence intervention strategies. ${ }^{1516}$

Longitudinal evaluation studies of the Cardiff Model in the UK demonstrated fewer violent crimes $^{17}$ and decreased number of patients with violent injuries. ${ }^{18}$ These outcomes were attributed to combined datadriven innovations in violence mitigation strategies, such as more representative hotspot maps for targeted police patrol. ${ }^{192}$ Additionally, the Cardiff Model in the UK has reduced the economic burden of violence by 6.9 million pounds (approximately US $\$ 9.6$ million) to the health service industry, criminal justice system and other sectors. $^{21}$

Despite its promise, there are barriers for successful translation of the Cardiff Model in the USA. The UK uses a national health system with unified data collection while the USA uses hybrid systems inclusive of a large private healthcare sector with different EHRs, fractured information sharing and competition for market share. Despite these variances, prior pilot studies suggest that successful replication of the Cardiff Model is possible in the USA, but additional feasibility evaluations are required across patient populations and US regions. ${ }^{13} 14$

\section{Potential impact of the Cardiff Model in the USA}

Valuable geospatial data collected through EDs can be leveraged by multidisciplinary community coalitions to enhance behavioural, environmental and policy-oriented and law enforcement-oriented violence prevention interventions. Data driven strategies implemented based on Cardiff Model-enhanced information include the establishment of targeted law enforcement patrolling areas, placement of closed-circuit television cameras, plastic bottles instead of glass at bars to decrease injury severity, expansion of sidewalk width to reduce crowding and development of 'green spaces' for gun violence deterrence. ${ }^{7223}$ These and similar violence reduction initiatives are successful at decreasing assault-related injuries. ${ }^{24}$ The Cardiff Model provides opportunities for open collaboration between hospitals and community violence prevention groups for mutually beneficial innovations and efficient utilisation of resources. ${ }^{25}$ Hospital acquired data may also assess effectiveness of interventions and allow for direct targeting of community areas with high violence rates. ${ }^{218} \mathrm{ED}$ data collection, therefore, is valuable and versatile for current violence prevention initiatives.

\section{PURPOSE}

The purpose of this study is to assess the feasibility of translating the Cardiff Model's information collection procedures into the EHR at a an urban, Midwestern adult level I trauma center in the USA. The study evaluates potential factors that may pose challenges to reliable information collection in an adult patient population and how those factors compare to similar investigations of adult and paediatric populations. ${ }^{1314}$ 


\section{METHODS}

\section{Study site selection}

We collected information from a 60-bed adult ED of an academic, medical school-affiliated, level I trauma care center in a large Midwestern city. This ED services the local community and the level I trauma distinction routes all adult life-threatening traumatic injuries from the surrounding region to this ED. The intervention was implemented during the initial triage portion of the ED visit.

\section{Implementation and integration into the ED}

EHR (EPIC Systems, Verona, Wisconsin) changes incorporated screening questions (eg, 'Are you here for an injury?', 'Is this injury related to an assault?') and created data collection fields to input incidentlevel information for patients with positive violent injury screening. Information collection occurred from May 2017 to June 2020. All nurses who used the Cardiff Model's process were surveyed to assess integration and implementation of the questions in the EHR. The survey questions included a 6-point Likerttype scale (eg, strongly disagree to strongly agree), which were recoded to dichotomous variables, such as 'agree' ('strongly agree', agree and 'somewhat agree') and 'disagree' ('strongly disagree', disagree and 'somewhat disagree'). Other questions used dichotomous answer choices (eg, 'satisfied' and 'dissatisfied'), frequency (eg, 'never', 'some of the time', 'most of the time' and 'all of time time') and time ranges. Questions within this survey were based on eight evidencebased feasibility domains of acceptability, demand, implementation, practicality, adaptation, integration, expansion and limited-efficacy testing ${ }^{26}$ and were used in previous feasibility evaluations of data collection in EDs. ${ }^{1314}$ Deidentified online survey administration was performed through Qualtrics in early 2020.

\section{Information collection, preparation and analysis}

Location and relevant deidentified information were extracted from the EHR monthly to assess feasibility and completion rate of the Cardiff Model's data collection procedures. The information was categorised as assault or non-assault and used exact spatial and temporal details of each unique injury. ArcMap for Desktop V.10.3.1 (ESRI, Redlands, California) was used to geocode location information and create density maps of assaults. Logistic regression models were used to determine if patient-level and injury-level factors affected missing injury location address over time (IBM SPSS Statistics V.21 software). The dichotomous variable for whether a patient's injury location address (ability to geocode) was not missing or was missing $(0,1)$ was regressed on gender, race, age in years, means of arrival, accompaniment, insurance payer status, trauma type, season, time of day and year to determine if age of model implementation (in years) had associations with information completeness.

\section{Patient and public involvement}

Patient and public involvement was not sought for these initial exploratory analyses of existing data and feasibility surveys.

\section{RESULTS}

\section{Implementation and integration into the ED}

One hundred fifty ED nurses were surveyed with a response rate of $16.7 \%$ (25 nurses). Table 1 shows that most surveyed nurses are satisfied with information collection protocols $(80 \% ; \mathrm{n}=20)$ and integration into workflow and EHR $(84 \% ; n=21)$. Most nurses agreed that they could sufficiently collect violence information $(88 \% ; n=22)$ and that this information was valuable for clinical care $(72 \%$; $\mathrm{n}=18)$. Most $(88 \% ; \mathrm{n}=22)$ agreed that implementation of the Cardiff Model's information collection procedures did not significantly interfere with their work. Table 2 shows the behavioural frequency results from the nurse feasibility survey. Many nurses $(60 \% ; n=15)$ completed the information collection module frequently for patients with assault. Nurses reported that information collection led to social work referrals more frequently than reports to police on the patient's behalf $(50 \%$ Never placing police reports; $4.5 \%$ Never referring to social work). Many nurses $(76.9 \% ; \mathrm{n}=20)$ screened patients for assault within $30 \mathrm{~s}$ and most nurses $(76.6 \%, \mathrm{n}=23)$ recorded additional incident-specific assaultive injury information (eg, location, weapon) within $1 \mathrm{~min}$. Additional nursing perspectives on information collection procedures were obtained from free response questions. Common themes in support for data collection include increased understanding of injury mechanism and/or extent and helping in violence prevention research to benefit the community. Common themes that critique data collection procedures include invasion of patient privacy, time consuming and low priority of data collection in high acuity patients.

\section{Information collection, preparation and analysis}

Three hundred and ninety-nine thousand eight hundred ED patients were seen during the study period and 2648 patients $(0.67 \%)$ screened positive for assaultive injury with information recorded in specific Cardiff EHR fields. One hundred ninety-eight patients were omitted before analyses due to age outside the range served by this ED (ages 18-115), with most being children below age 18 . Table 3 shows patient demographic distributions and injury information. Most participants were men $(75.9 \%$; $\mathrm{n}=2010)$, black (50.2\%; $\mathrm{n}=1327)$, arrived/transported by ambulance $(68.5 \% ; \mathrm{n}=1812)$, arrived alone $(54.9 \%$; $\mathrm{n}=1452)$, had public insurance $(55.9 \% ; \mathrm{n}=1460)$ and experienced penetrating trauma $(56.8 \% ; n=1505)$. Of the 2648 cases, $825(31.2 \%)$ had enough information to be geocoded while $1823(68.8 \%)$ had insufficient street-level address information. Table 4 shows the results of a binomial logistic regression analysis comparing cases that were geocoded (0) versus those with missing address information (1). The overall logistic regression 
Table 1 Nurse feasibility survey dichotomous results

\section{Questions}

How satisfied are you with your participation in the collection of Injury/Trauma Assessment data in the ED?

(Acceptability)

How satisfied are you with the Injury/Trauma Assessment questions in EPIC? (Acceptability)

\section{Responses}

Satisfied

Dissatisfied

$\mathrm{N}=20(80.0 \%) \quad \mathrm{N}=5(20.0 \%)$

(A)

Patients and their families find it acceptable when I ask the Injury/Trauma Assessment questions.

(Acceptability)

I feel that patients and their families answer the Injury/Trauma Assessment questions honestly. (Acceptability)

I would like to see summary data reports that are generated from the Injury/Trauma Assessment questions. (Demand)

Patients are cooperative when asked the Injury/Trauma Assessment questions. (Practicality)

$\mathrm{N}=20(80.0 \%) \quad \mathrm{N}=5(20.0 \%)$

I am able to collect the Injury/Trauma Assessment information from patients. (Implementation)

Agree Disagree

I am able to record patient responses to the Injury/Trauma Assessment questions into the Epic system. (Implementation)

Collection of the Injury/Trauma Assessment questions is integrated into the workflow within the ED. (Integration)

Collection of the Injury/Trauma Assessment questions within the ED could continue over the next year. (Expansion)

Collection of the Injury/Trauma Assessment questions within the ED should continue over the next year. (Demand)

\begin{tabular}{|c|c|c|}
\hline $\begin{array}{l}\text { Collection of Injury/Trauma Assessment data is congruent with the goals and mission of my ED and hospital. } \\
\text { (Acceptability) }\end{array}$ & $\mathrm{N}=23(92 \%)$ & $\mathrm{N}=2(8 \%)$ \\
\hline $\begin{array}{l}\text { The information collected in the Injury/Trauma Assessment module is useful for clinical care in the ED. } \\
\text { (Demand) }\end{array}$ & $\mathrm{N}=18(72 \%)$ & $\mathrm{N}=7(28 \%)$ \\
\hline Hospital staff should collect data on assault and injury. (Acceptability) & $\mathrm{N}=22(91.2 \%)$ & $\mathrm{N}=2(8.8 \%)$ \\
\hline I am interested in collecting assault and injury data in my everyday work. (Acceptability) & $\mathrm{N}=20(83.3 \%)$ & $\mathrm{N}=4(16.7 \%)$ \\
\hline Patients want ED staff to help them with reporting violence and injury to the police. (Demand) & $\mathrm{N}=14(58.3 \%)$ & $\mathrm{N}=10(41.7 \%)$ \\
\hline
\end{tabular}

ED, emergency department.

model was significant by the Omnibus test, $x^{2}(\mathrm{df}=26$, $\mathrm{n}=2648)=289.391, \mathrm{p}<0.001$, indicating that one or more predictor reliably distinguished between those with and those without injury location information that could be geocoded. Specifically, men were 0.746 times as likely to have missing injury locations compared with women $(\mathrm{p}=0.04)$. African American or black race $(\mathrm{OR}=0.511)$, hispanic ethnicity $(\mathrm{OR}=0.477)$ and those identifying as 'other' race $(\mathrm{OR}=0.406)$ were less likely to have missing injury addresses compared with their white counterparts. Participants transported by helicopter, such as Flight for Life or equivalent service, were 7.722 times as likely to have missing location data compared with those arriving by personal car $(\mathrm{p}=0.001)$. Patients accompanied by friends were 3.878 times as likely to have missing location data compared with those arriving alone $(\mathrm{p}=0.009)$.

Table 2 Nurse feasibility survey frequency results

\begin{tabular}{|c|c|c|c|c|}
\hline \multirow[b]{2}{*}{ Questions } & \multicolumn{4}{|l|}{ Responses } \\
\hline & Never & $\begin{array}{l}\text { Some of } \\
\text { the time }\end{array}$ & $\begin{array}{l}\text { Most of } \\
\text { the time }\end{array}$ & $\begin{array}{l}\text { All of the } \\
\text { time }\end{array}$ \\
\hline $\begin{array}{l}\text { Since data collection first started, how often does Injury/Trauma Assessment questions } \\
\text { result in a report to the police on the patient's behalf? (Adaptation) }\end{array}$ & $\mathrm{N}=7(50 \%)$ & $\begin{array}{l}\mathrm{N}=6 \\
(42.9 \%)\end{array}$ & $\mathrm{N}=0(0 \%)$ & $\begin{array}{l}\mathrm{N}=1 \\
(7.1 \%)\end{array}$ \\
\hline $\begin{array}{l}\text { How often do patients refuse to answer one or more of the Injury/Trauma Assessment } \\
\text { questions? (Implementation) }\end{array}$ & $\mathrm{N}=6(24 \%)$ & $\begin{array}{l}N=17 \\
(68 \%)\end{array}$ & $\mathrm{N}=2(8 \%)$ & $\mathrm{N}=0(0 \%)$ \\
\hline
\end{tabular}


Table 3 Distribution of patients screening positive for assault injury by demographic and injury-related data

\section{Total $\mathbf{N}=2648$}

\begin{tabular}{ll}
\hline $\begin{array}{l}\text { Gender } \\
\text { Male }\end{array}$ & $\mathrm{n}=2010(75.9 \%)$ \\
Female & $\mathrm{n}=637(24.1 \%)$
\end{tabular}

Race

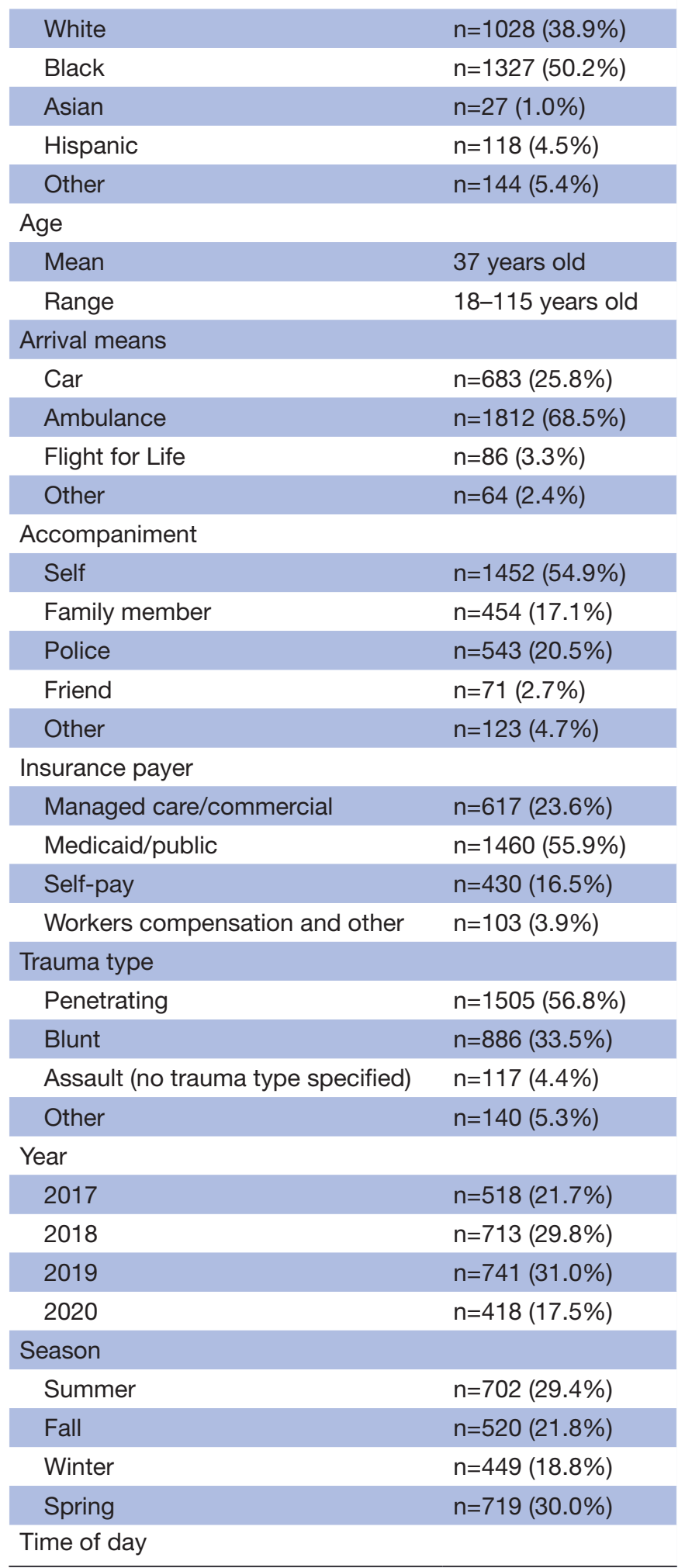

Continued
Table 3 Continued

\begin{tabular}{ll}
\hline Total $\mathbf{N}=\mathbf{2 6 4 8}$ & \\
\hline Day $(7 a-7 p)$ & $n=1024(55.4 \%)$ \\
Night $(7 p-7 a)$ & $n=826(44.6 \%)$ \\
Able to geocode & \\
Yes & $n=825(31.2 \%)$ \\
No & $n=1823(68.8 \%)$ \\
\hline
\end{tabular}

Patients with blunt or other trauma types were 2.13 $(\mathrm{p}<0.001)$ and $1.869(\mathrm{p}=0.019)$ times as likely to have missing location information compared with those with penetrating trauma. Those presenting with assaultive trauma were 0.513 times as likely to have missing location data compared with penetrative injuries $(\mathrm{p}=0.009)$. Referral years 2018, 2019 and 2020 were less likely to have missing location data compared with 2017 (OR=0.337; $\mathrm{OR}=0.438$; and $\mathrm{OR}=0.597$, respectively). Insurance payer method, season of injury and time of day were not significantly associated with injury location completeness.

\section{DISCUSSION}

This study found that implementation of the Cardiff Model's information collection procedures in a Midwest US level 1 trauma tertiary care center adult ED is feasible with minimal disturbance to nursing staff. To our knowledge, this is the first evaluation of patient-level and assault incident-level variables associated with completeness of assault location information captured in an adult US ED. Two prior studies have shown Cardiff information collection feasibility in both adult and paediatric EDs. ${ }^{13} 14$ However, only paediatric patient data have been analysed to show data quality and completion rates of gathering injury information. We show that there are unique patient and incident-level variables associated with completeness of adult location information when compared with paediatric information.

\section{Implementation and integration into the ED}

This study's quantitative analyses suggest that information collection procedures can be successfully integrated into the EHR without significant workflow obstruction. Many surveyed nurses spent less than $30 \mathrm{~s}$ for initial screening procedures. When screening tests were positive, all nurses obtained and inputted relevant assaultive injury information into the EHR within 3 min. ED nurses reported that gathering assaultive information was feasible and that Cardiff data had additional benefits, such as determining injury mechanism and guiding social work referrals. Nurses found the process to be professionally rewarding and impactful for their community's safety, with a majority agreeing on continued data collection importance over the next year. However, some nurses reported limitations in information collection from high acuity patients, which is expected in an acute hospital setting. Future information collection updates could include additional 
Table 4 Logistic regression model comparing injury cases with reported addresses versus no available address

\begin{tabular}{|c|c|c|c|c|c|c|c|}
\hline Independent variables & B & SE & Wald $\left(\chi^{2}\right.$ test) & df & Significance & $\operatorname{Exp}(B)(O R)$ & $95 \% \mathrm{Cl}$ \\
\hline Gender (male) & -0.293 & 0.14 & 4.411 & 1 & 0.036 & 0.746 & 0.567 to 0.981 \\
\hline Race (white-reference group) & & & 20.729 & 4 & 0.000 & & \\
\hline Race (Asian) & -0.831 & 0.498 & 2.778 & 1 & 0.096 & 0.436 & 0.164 to 1.157 \\
\hline Race (hispanic) & -0.673 & 0.28 & 5.768 & 1 & 0.016 & 0.51 & 0.295 to 0.884 \\
\hline Age in years & -0.002 & 0.004 & 0.351 & 1 & 0.554 & 0.998 & 0.99 to 1.006 \\
\hline Arrival means (car-reference group) & & & 13.726 & 3 & 0.003 & & \\
\hline Arrival means (ambulance) & -0.181 & 0.192 & 0.889 & 1 & 0.346 & 0.834 & 0.573 to 1.216 \\
\hline Arrival means (Flight for Life) & 2.044 & 0.635 & 10.37 & 1 & 0.001 & 7.722 & 2.226 to 26.793 \\
\hline Arrival means (other) & -0.211 & 0.429 & 0.241 & 1 & 0.623 & 0.81 & 0.349 to 1.879 \\
\hline Presence of other people (friend) & 1.355 & 0.515 & 6.921 & 1 & 0.009 & 3.878 & 1.413 to 10.646 \\
\hline Presence of other people (other) & 0.484 & 0.279 & 3.004 & 1 & 0.083 & 1.623 & 0.939 to 2.805 \\
\hline $\begin{array}{l}\text { Insurance payer (managed care/commercial- } \\
\text { reference group) }\end{array}$ & & & 0.62 & 3 & 0.892 & & \\
\hline Insurance payer (medicaid/public) & -0.123 & 0.164 & 0.558 & 1 & 0.455 & 0.885 & 0.641 to 1.220 \\
\hline Insurance payer (self-pay) & -0.06 & 0.196 & 0.092 & 1 & 0.761 & 0.942 & 0.641 to 1.384 \\
\hline Insurance payer (other) & -0.104 & 0.333 & 0.097 & 1 & 0.756 & 0.902 & 0.469 to 1.732 \\
\hline Trauma type (penetrating-reference group) & & & 35.138 & 3 & 0.000 & & \\
\hline Trauma type (blunt) & 0.756 & 0.159 & 22.695 & 1 & 0.000 & 2.13 & 1.561 to 2.908 \\
\hline Season (summer-reference group) & & & 3.164 & 3 & 0.367 & & \\
\hline Season (fall) & 0.164 & 0.157 & 1.096 & 1 & 0.295 & 1.178 & 0.867 to 1.601 \\
\hline Season (winter) & 0.285 & 0.168 & 2.891 & 1 & 0.089 & 1.33 & 0.957 to 1.849 \\
\hline Season (spring) & 0.181 & 0.155 & 1.364 & 1 & 0.243 & 1.198 & 0.884 to 1.624 \\
\hline Time (day 7a-7p) & 0.133 & 0.115 & 1.356 & 1 & 0.244 & 1.143 & 0.913 to 1.430 \\
\hline
\end{tabular}

Bold results indicate statistically significant findings at $\mathrm{p}<0.05$.

collection points at separate times during the ED course, such as discharge or admission, to capture any missed information from triage.

\section{Data collection, preparation and analysis}

Patient-reported gender, race, age, arrival method, presence of other people, trauma type and year were associated with missingness of injury location information. All patients presenting to the ED were screened, thereby mitigating any selection bias in our study population. Male gender was less likely to have missing injury location data compared with women. The aetiology of this gender asymmetry is unclear, but it may be associated with psychosocial factors that influence the type of violence experienced (eg, domestic violence vs assault by a stranger). Black, hispanic and other ethnicities were less likely to have missing data when compared with their Caucasian counterparts, which may be explained by nursing staff bias to obtain location data disproportionately based on ethnicity. ${ }^{27}$ Patients arriving via Flight for Life (or any helicopter-based transportation) were significantly more likely to have missing location information. Patients requiring air transportation are usually critically ill, medically complex and require life-saving intervention. Therefore, medical stabilisation is prioritised over 
obtaining other data. Friend accompaniment in the ED had increased missing data compared with those alone in the ED. Complex peer relationships and unwillingness to disclose an injury location that was a friend's home address may have impacted data completeness. Different trauma injury types had different likelihoods of obtaining location information. Injury categories are not mutually exclusive and often have some degree of overlap. Therefore, the relationship between data completeness and injury type may be affected by subjectivity and variation in nursing preference for certain category schemes. The years following 2017-initial year of implementationshowed significantly reduced odds of missing location data, which may reflect increased nurse familiarity with the questions over time and repeated training on information collection. This also aligns with the 2020 survey showing satisfaction on integration into the ED workflow.

\section{Prior implementation in a United States Pediatric Hospital: similarities and differences}

Similar Cardiff data collection procedures have been successfully implemented at a tertiary care, level one trauma paediatric ED in the same large Midwestern city as this study. The prior study by Levas et al demonstrated that race, insurance payer, injury time and injury type had significant impacts on the likelihood of obtaining viable injury locations. ${ }^{14}$ Both studies agreed that race and injury type played significant roles in determining likelihood of obtaining injury location data. Similarly, minority populations (Asian in Levas et al and black, hispanic and other in our study) were significantly less likely to have missing location data relative to their white counterparts, which additionally may be due to bias in nursing staff data collection. Further research is needed to determine the impact of these subgroups on injury location availability.

Data suggests that age may be a confounding variable for the differences found between the adult and paediatric studies. Children in the ED are often accompanied by parents or guardians who provide consent (required for patients under age 18), whereas adult patients generally provide consent themselves. Therefore, parent/ guardian accompaniment occurs regardless of transportation method, which may have the added benefits of providing supplemental injury information. This is shown by arrival means and accompaniment being significant for missing information only in the adult population.

Insurance payer significance on location information completeness was different between the adult and paediatric EDs. Paediatric patients with public insurance or Medicaid were twice as likely to have missing location data while insurance type did not significantly affect the adult population. Insurance payer should theoretically be consistent between the two groups since the same insurance modalities are used. Further research is needed to elucidate the significance of insurance payer on address availability.

To our knowledge, the study by Levas $e t$ al is the only additional study that has analysed data quality and completion rates of Cardiff Model data collection procedures. They demonstrate the ability to capture sufficient data to geocode and map $66.3 \%$ of cases, which is approximately double to our capture rate of $31.2 \%$. We attribute this to increased patient volume in the adult ED setting. Levas et al screened 8758 patients per month and attempted to collect injury data for 58 patients per month. Our study screened 10805 patients per month and attempted to collect injury data for 72 patients per month. Additionally, the differences in data completion rates may be multifactorial, which include differences in departmental culture, patient acuity and patient demographics. Currently, it is unclear if our capture percentage is enough to improve targeted community violence interventions. However, we anticipate that this initial study may have enough data to provide a better understanding of community violence.

\section{Limitations}

One limitation of the analysis is the low survey response rate of ED nurses, which may not accurately portray the larger population of nurses at this hospital. However, difficulties with collecting survey data from medical staff have been documented, and our rate of $16.7 \%$ is higher than the average medical practitioner response rate of $8.7 \%{ }^{28}$ Although physical surveying (eg, pen and paper) offers higher response rates, we opted for electronic surveying due to ease of use and varying shift times of the ED nurses. While nurses indicted that they are willing and able to collect the Injury/Trauma Assessment information, we are unable to run a compliance report to determine actual integration into workflow. Our study was conducted in a single adult level I trauma center $\mathrm{ED}$, which may not be generalisable to other hospitals. However, we believe that our results are generalisable to other trauma centres and community EDs. All US trauma centres are required or encouraged to have research in trauma care, which can be achieved with implementation of the Cardiff Model.

\section{Conclusion}

It appears feasible to implement assault-related injuryspecific information collection into the triage portion ED visit by adults. Information collection procedures do not significantly disrupt triage nurse workflow. Nurses are receptive to participating in the collection of this data, which may help guide clinical care and community violence prevention strategies. Variables that significantly contributed to successfully obtaining location data were gender (men), race (black, ispanic, other), trauma type (assault) and number of years following implementation. Variables that significantly contributed to missing location data were arrival means (helicopter), presence of friends and trauma type (blunt and other). This variation in response rates should be considered when implementing similar ED-based information collection procedures by nurses in the EHR. 
Acknowledgements The ED nurses at the study site collaborated with the authors and collected the emergency department data used in this study. Jamie Aranda, MD, served a dedicated Physician Champion for the study. The authors would like to thank local health departments, agencies, emergency medical services and police departments, as well as their staff, who provided valuable ongoing partnership for the described violence prevention activities.

Contributors PN contributed to the acquisition, statistical analysis, and interpretation of data and drafting the manuscript. SAK contributed to the study concept and design and acquisition of data. ML contributed to the study concept and design. JH-M served as the guarantor and contributed to the study concept and design, obtaining funding, and provided supervision of the study. All authors contributed revised the manuscript.

Funding This work was supported by the US Department of Justice National Institute of Justice and the Bureau of Justice Assistance, Office of Justice Programs grant numbers 2014-IJ-CX-0110, 2016-AJ-BX-K042, and 2018-AR-BX-K106.

Disclaimer The opinions, findings, and conclusions or recommendations expressed in this publication are those of the author(s) and do not necessarily reflect those of the Department of Justice.

Competing interests None declared.

Patient and public involvement Patients and/or the public were not involved in the design, or conduct, or reporting, or dissemination plans of this research.

Patient consent for publication Not applicable.

Ethics approval Research activities were reviewed and approved by the medical school's Institutional Review Board \#PR000023724. A waiver of consent and assent were obtained since the information was deidentified and the research team had no direct patient interactions for information collection procedures.

Provenance and peer review Not commissioned; externally peer reviewed.

Data availability statement Data may be obtained from a third party and are not publicly available. Data is not publicly available. Froedtert \& the Medical College of Wisconsin health system should be contacted directly for data requests.

Open access This is an open access article distributed in accordance with the Creative Commons Attribution Non Commercial (CC BY-NC 4.0) license, which permits others to distribute, remix, adapt, build upon this work non-commercially, and license their derivative works on different terms, provided the original work is properly cited, appropriate credit is given, any changes made indicated, and the use is non-commercial. See: http://creativecommons.org/licenses/by-nc/4.0/.

\section{ORCID iDs}

Peter Nguyen http://orcid.org/0000-0002-6763-7167

Sara A Kohlbeck http://orcid.org/0000-0003-0301-0362

Jennifer Hernandez-Meier http://orcid.org/0000-0003-1709-3576

\section{REFERENCES}

1 Morgan RE, Oudekerk BA. Criminal victimization, 2018. Washington, DC: U.S. Department of Justice, Office of Justice Programs, Bureau of Justice Statistics, 2018.

2 Bowen DA, Mercer Kollar LM, Wu DT, et al. Ability of crime, demographic and business data to forecast areas of increased violence. Int J Inj Contr Saf Promot 2018;25:443-8.

3 Gray BJ, Barton ER, Davies AR, et al. A shared data approach more accurately represents the rates and patterns of violence with injury assaults. J Epidemiol Community Health 2017;71:1218-24.

4 Wu DT, Moore JC, Bowen DA, et al. Proportion of violent injuries unreported to law enforcement. JAMA Intern Med 2019;179:111-2.

5 Sutherland I, Sivarajasingam V, Shepherd JP. Recording of community violence by medical and police services. Inj Prev 2002;8:246-7.

6 Sugimoto-Matsuda JJ, Braun KL. The role of collaboration in facilitating policy change in youth violence prevention: a review of the literature. Prev Sci 2014;15:194-204.
7 Sumner SA, Mercy JA, Dahlberg LL, et al. Violence in the United States: status, challenges, and opportunities. JAMA 2015;314:478-88.

8 Affinati S, Patton D, Hansen L, et al. Hospital-based violence intervention programs targeting adult populations: an eastern association for the surgery of trauma evidence-based review. Trauma Surg Acute Care Open 2016;1:e000024.

9 Goins WA, Thompson J, Simpkins C. Recurrent intentional injury. J Natl Med Assoc 1992;84:431-5.

10 WISQARS. Nonfatal injury reports, 2000-2018. Atlanta, GA: Centers for Disease Control and Prevention, National Center for Injury Prevention and Control, 2018.

11 Goodwin V, Shepherd JP. The development of an assault patient questionnaire to allow accident and emergency departments to contribute to crime and disorder act local crime audits. J Accid Emerg Med 2000;17:196-8.

12 Quigg Z, Hughes K, Bellis MA. Data sharing for prevention: a case study in the development of a comprehensive emergency department injury surveillance system and its use in preventing violence and alcohol-related harms. Inj Prev 2012;18:315-20.

13 Mercer Kollar LM, Sumner SA, Bartholow B, et al. Building capacity for injury prevention: a process evaluation of a replication of the Cardiff violence prevention programme in the southeastern USA. Inj Prev 2020;26:221-8.

14 Levas MN, Hernandez-Meier JL, Kohlbeck S, et al. Integrating population health data on violence into the emergency department: a feasibility and implementation study. J Trauma Nurs 2018;25:149-58.

15 Kollar LMM, Sumner SA. Cardiff model toolkit: community guidance for violence prevention. Atlanta, GA: Division of Violence Prevention, National Center for Injury Prevention and Control, Centers for Disease Control and Prevention, 2018.

16 Shepherd JP, Sumner SA. Policing and public Health-Strategies for collaboration. JAMA 2017;317:1525-6.

17 Boyle AA, Snelling K, White L, et al. External validation of the Cardiff model of information sharing to reduce community violence: natural experiment. Emerg Med J 2013;30:1020-3.

18 Florence C, Shepherd J, Brennan I, et al. Effectiveness of anonymised information sharing and use in health service, police, and local government partnership for preventing violence related injury: experimental study and time series analysis. BMJ 2011;342:d3313.

19 Warburton AL, Shepherd JP. Development, utilisation, and importance of accident and emergency department derived assault data in violence management. Emerg Med J 2004;21:473-7.

20 Jacoby SF, Kollar LMM, Ridgeway G, et al. Health system and law enforcement synergies for injury surveillance, control and prevention: a scoping review. Inj Prev 2018;24:305-11.

21 Florence C, Shepherd J, Brennan I, et al. An economic evaluation of anonymised information sharing in a partnership between health services, police and local government for preventing violence-related injury. Inj Prev 2014;20:108-14.

22 Aboutanos MB, Jordan A, Cohen R, et al. Brief violence interventions with community case management services are effective for high-risk trauma patients. J Trauma 2011;71:228-37.

23 Sivarajasingam V, Shepherd JP, Matthews K. Effect of urban closed circuit television on assault injury and violence detection. Inj Prev 2003;9:312-6.

24 Rainey SR, Simpson J, Page S, et al. The impact of violence reduction initiatives on emergency department attendance. Scott Med J 2015;60:90-4.

25 Rosenblatt MS, Joseph KT, Dechert T, et al. American association for the surgery of trauma prevention Committee topical update: impact of community violence exposure, intimate partner violence, hospital-based violence intervention, building community coalitions and injury prevention program evaluation. J Trauma Acute Care Surg 2019;87:456-62.

26 Bowen DJ, Kreuter M, Spring B, et al. How we design feasibility studies. Am J Prev Med 2009;36:452-7.

27 Groves PS, Bunch JL, Sabin JA. Nurse bias and nursing care disparities related to patient characteristics: a scoping review of the quantitative and qualitative evidence. J Clin Nurs 2021;30:3385-97.

28 Aitken C, Power R, Dwyer R. A very low response rate in an on-line survey of medical practitioners. Aust $N Z J$ Public Health 2008;32:288-9. 